\title{
Tissue-Type Plasminogen Activator Increases the Binding of Glu-Plasminogen to Clots
}

\author{
Chiên Tran-Thang, Egbert K. O. Kruithof, \\ and Fedor Bachmann \\ Laboratoire Central d'Hématologie, CHUV, \\ CH-1011 Lausanne, Switzerland
}

bstract. Porcine tissue-type plasminogen activator (t-PA) increases the binding of ${ }^{125} \mathrm{I}$-glu-plasminogen to clots made from human plasma or purified fibrinogen in a time and t-PA concentration dependent fashion. The accumulation of plasminogen was faster and greater on noncrosslinked plasma clots than on clots which had been crosslinked by Factor XIIIa. Furthermore, the uptake of plasminogen to crosslinked fibrin clots occurred at a slower rate in the presence of $\alpha_{2}$-plasmin inhibitor $\left(\alpha_{2} \mathrm{PI}\right)$ than in its absence. The kinetics of the uptake of ${ }^{125} \mathrm{I}$-plasminogen were analyzed using SDS-polyacrylamide gel electrophoresis and radioautography of solubilized plasma clots formed in the presence of t-PA. During the initial phase there was a decrease of clot-bound glu-plasminogen; simultaneously, there was a slight increase in clot-bound glu-plasmin and in plasmin complexed to $\alpha_{2}$ PI that was crosslinked to $\alpha$-chain polymers of fibrin. This was followed by a marked increase in clot-bound plasminogen having glutamic acid as $\mathrm{NH}_{2}$-terminal (glu-plasminogen) and gluplasmin. t-PA-induced enhancement of glu-plasminogen uptake appears to be mediated by plasmin but does not require the conversion of glu-plasminogen to plasminogen having lysine or methionine as $\mathrm{NH}_{2}$-terminal. The described mechanism assures an adequate supply of clot-bound plasmin, which is the enzyme ultimately involved in the degradation of fibrin.

This work was presented in part at the Satellite Symposium "Fibrinogen and its Degradation Products-Structure and Function" at the IXth Congress of the International Society on Thrombosis and Haemostasis, Stockholm, Sweden, 1983.

Address correspondence to Dr. Tran-Thang.

Received for publication 28 March 1984 and in revised form 21 August 1984.

J. Clin. Invest.

(c) The American Society for Clinical Investigation, Inc. 0021-9738/84/12/2009/07 $\$ 1.00$

Volume 74, December 1984, 2009-2016

\section{Introduction}

During blood coagulation, $\sim 30 \%(0.2 \mu \mathrm{mol} / \mathrm{l})$ of plasma $\alpha_{2}$-plasmin inhibitor $\left(\alpha_{2} \mathrm{PI}\right)^{1}$ are crosslinked to $\alpha$-chain polymers of fibrin (1); an equimolar amount of plasminogen having glutamic acid as $\mathrm{NH}_{2}$-terminal (glu-plasminogen) is bound to fibrin (10\% of plasma concentration or $0.2 \mu \mathrm{mol} / \mathrm{l})(2)$. The amount of fibrin-bound $\alpha_{2}$ PI thus suffices to inhibit all plasmin generated from fibrin-bound plasminogen (2).

Tissue-type plasminogen activator (t-PA) mediates specific and efficient thrombolysis (3-8). This process is dependent on fibrin-bound plasmin which is protected against the inhibitory effect of circulating $\alpha_{2}$ PI (9-11). An excess of plasminogen or of plasmin is therefore needed at the fibrin surface to bring about fibrin degradation. The rapid complexation of circulating plasmin by $\alpha_{2}$ PI precludes accumulation of active plasmin on fibrin (9-11). Several authors postulated that the conversion of glu-plasminogen into plasminogen having lysine or methionine as $\mathrm{NH}_{2}$-terminal (lys-plasminogen), which adsorbs to fibrin to a greater extent than the glu-form (12-18), would ensure an additional supply of plasminogen onto the clot.

In this report, we have investigated an alternative hypothesis, i.e., whether porcine t-PA promotes the uptake of glu-plasminogen onto fibrin.

\section{Methods}

Materials. Materials were supplied as follows: imidazole, epsilonaminocaproic acid (EACA), L-lysine-HCl (puriss), ethylenediamine tetraacetic acid disodium salt (EDTA, puriss), diisopropylfluorophosphate (DFP), calcium chloride (purum), 2-mercaptoethanol (puriss) and, bovine serum albumin (BSA, fraction V) from Fluka, Buchs, Switzerland; sodium chloride, urea, acetic acid, trichloroacetic acid (20\%), and hydrochloric acid (proanalysi) from Merck, Darmstadt,

1. Abbreviations used in this paper: DFP, diisopropylfluorophosphate; EACA, epsilon-aminocaproic acid; FSF, fibrin-stabilizing factor; gluplasminogen, plasminogen having glutamic acid as NH-terminal; lysplasminogen, plasminogen having lysine or methionine as $\mathrm{NH}$-terminal; $\alpha_{2} \mathrm{PI}, \alpha_{2}$-plasmin inhibitor, SDS-PAGE, SDS-polyacrylamide electrophoresis; t-PA, tissue-type plasminogen activator. 
Federal Republic of Germany; Topostasin, a crude thrombin preparation which was found to be free of plasminogen activator when analyzed by the Granelli-Piperno method $(8,19)$, from Hoffmann-La Roche, Basel, Switzerland; ${ }^{125}$ I-fibrinogen (FIBI-125C, 80-90\% clottable) from Sorin Biomedica, Saluggia, Italy; $\mathrm{Na}{ }^{125} \mathrm{I}(17.4 \mathrm{Ci} / \mathrm{mg}$ in $0.1 \mathrm{~N}$ sodium hydroxyde) from New England Nuclear, Boston, MA; $\beta$-D(+) glucose and aprotinin (Trasylol) from Bayer, Leverkusen, Federal Republic of Germany; affinity purified bovine lung aprotinin and Tween 80 from Sigma Chemical Co., St. Louis, MO; fibrinogen (human, grade L, 8090\% clottable) and H-D-Val-Leu-Lys-pNA (S-2251) from Kabi, Stockholm, Sweden; antisera against Factor XIII (fibrin-stabilizing factor [FSF]) and agarose grade L from Behringwerke, Marburg, Federal Republic of Germany; Biogel P-300, all reagents for SDS-polyacrylamide gel electrophoresis (SDS-PAGE) and immobilized lactoperoxidase/ glucose oxidase (Enzymobeads) used for radioiodination from BioRad Laboratories, Richmond, CA; Sephadex G-100 and lysine-Sepharose 4B from Pharmacia, Uppsala, Sweden. The lys-form of plasminogen (NIBSC, code 66/234), the International Standard for human t-PA (NIBSC, code 83/517, 1,000 IU/ampoule), and the 2nd International Standard for plasmin (NIBSC, code 77/588, $10 \mathrm{IU} /$ ampoule) were provided by Dr. P. J. Gaffney of the National Institute for Biological Standards and Control, London, United Kingdom. The amino-terminal of the lys-plasminogen preparation contained $\sim 50 \%$ lysine and $50 \%$ methionine (kindly determined by Dr. E. Rickli, Institute for Biochemistry, Bern, Switzerland). Human $\alpha_{2}$ PI was donated by Drs. D. Collen and H. R. Lijnen from the Center for Thrombosis and Vascular Research, Leuven, Belgium. High $M_{\mathrm{r}}$-urokinase $(100,000 \mathrm{IU} / \mathrm{mg})$ was generously supplied by Dr. D. Sauser, Serono Laboratories, Coinsins, Switzerland. All concentrations given in this paper are final. The imidazole buffer $\mathrm{pH} 7.35$ used for many experiments contained 0.05 $\mathrm{M}$ imidazole and $0.14 \mathrm{M} \mathrm{NaCl}, \mathrm{pH} 7.35$.

Human plasma. Blood was obtained from healthy donors. It was anticoagulated with sodium citrate-phosphate-dextrose-adenine (Travenol, Caslehar, Ireland). Platelet-poor plasma was obtained by centrifugation for $30 \mathrm{~min}$ at $3,600 \mathrm{~g}$ and $4^{\circ} \mathrm{C}$. In some experiments, $10 \mathrm{mM}$ EDTA was added to plasma. The fibrinogen concentration of the three plasma pools (nine donors for each pool) used in the experiments, as measured by the Clauss method, was between 1.8 and $2 \mathrm{~g} / \mathrm{l}$.

FSF-deficient plasma was kindly provided by Dr. F. Duckert of the Coagulation Laboratory, Kantonsspital, Basel, Switzerland, who found it to contain < $1 \%$ FSF compared with normal plasma by a method measuring the incorporation of dansyl cadaverine.

Glu-plasminogen. Glu-plasminogen was prepared from fresh-frozen plasma by affinity chromatography on lysine-Biogel by the method of Deutsch and Mertz (20). All purification steps were performed in the presence of $10 \mathrm{mM}$ DFP and $150 \mathrm{KIU} / \mathrm{ml}$ aprotinin, except for the final dialysis against imidazole buffer. The amino-terminal was glutamic acid, as characterized by the dansyl chloride method (21). Its specific activity was $14 \mathrm{IU}$ plasmin/mg. Plasminogen was determined after its conversion into plasmin by urokinase (22). This was accomplished by incubating the purified plasminogen $(0.5 \mathrm{mg} / \mathrm{ml})$ with various urokinase concentrations $(1,000,2,000$, and $4,000 \mathrm{IU} / \mathrm{ml})$ in $50 \mathrm{mM}$ phosphate$10 \mathrm{mM}$ EACA, $\mathrm{pH} 8.2$ at $37^{\circ} \mathrm{C}$. Aliquots were removed after $2,5,10$, and $15 \mathrm{~min}$, diluted 250 -fold, and added to the chromogenic substrate $\mathrm{S}-2251(0.6 \mathrm{mM})$ in $50 \mathrm{mM}$ Tris $\mathrm{HCl}-12 \mathrm{mM} \mathrm{NaCl}, \mathrm{pH} \mathrm{7.4,} \mathrm{containing}$ $0.01 \%$ Tween 80 . The initial rate of substrate conversion was measured in a recording spectrophotometer at a wavelength of $405 \mathrm{~nm}$. The highest values were selected for comparison with the initial rate of S-2251 conversion by the International plasmin reference preparation. The glu-plasminogen was radioiodinated by the lactoperoxidase/glucose oxidase method $(12,23)$. One-fifth of a milliliter of glu-plasminogen $(1 \mathrm{mg} / \mathrm{ml})$ was mixed with $10 \mu \mathrm{l}$ of carrier free $\mathrm{Na}^{125} \mathrm{I}(1 \mathrm{mCi}), 75 \mu \mathrm{l}$ of $\beta$-D $(+)$ glucose $(1 \%)$, and $75 \mu$ l of Enzymobeads, and incubated at room temperature for $15 \mathrm{~min}$. The beads were removed by centrifugation at $3,600 \mathrm{~g}$ for $5 \mathrm{~min}$. Radioiodinated plasminogen was separated from unbound ${ }^{125} \mathrm{I}$ on a $25 \mathrm{ml}$ Sephadex G-100 column using imidazole buffer that contained $0.1 \%$ BSA and $0.05 \%$ sodium azide. The incorporation of ${ }^{125}$ I into the plasminogen molecules varied between 7 and $20 \%$ of the $\mathrm{Na}{ }^{125} \mathrm{I}$ added, and the specific radioactivity between 0.3 $\mathrm{mCi}$ and $2 \mathrm{mCi} / \mathrm{mg}$ plasminogen (one atom to eight atoms of ${ }^{125} \mathrm{I}$ per 100 molecules of plasminogen). The ${ }^{125}$ I-plasminogen had the same electrophoretic mobility as unlabeled glu-plasminogen in SDS-PAGE and in urea/acetic acid electrophoresis. Labeled glu-plasmin and lysplasmin were made as follows: ${ }^{125}$ I-plasminogen was added to a solution of unlabeled plasminogen $(3.25 \mathrm{mg} / \mathrm{ml})$ and incubated at $37^{\circ} \mathrm{C}$ for $1 \mathrm{~h}$ with $0.1 \mathrm{M}$ lysine monochloride and $150 \mathrm{IU} / \mathrm{ml}$ of urokinase in the presence or absence of aprotinin. In the absence of aprotinin, ${ }^{125} \mathrm{I}$-plasminogen was converted into lys-plasmin, whereas, in the presence of $10,000 \mathrm{KIU} / \mathrm{ml}$ aprotinin, glu-plasmin was formed. After reduction by 2-mercaptoethanol, these samples were subjected to SDS-PAGE in a $12.5 \%$ separating gel followed by staining in Coomassie Blue and radioautography as described in the "Electrophoretic procedure and radioautography" section. This allowed the comparison of the conversion of unlabeled and labeled glu-plasminogen into plasmin by urokinase and the determination of the relative radioactivities related to the different domains of the ${ }^{125} \mathrm{I}$-plasminogen molecule. In the presence of aprotinin, $67 \pm 2 \%$ (mean \pm SD of quadruplicate experiments) of ${ }^{125} \mathrm{I}$-glu-plasminogen was converted into ${ }^{125} \mathrm{I}-$ glu-plasmin (heavy chain $67 \%$, light chain $33 \%$ ) by urokinase. In the absence of aprotinin, $93 \pm 4 \%$ of ${ }^{125} \mathrm{I}$-glu-plasminogen was activated into ${ }^{125}$ I-lys-plasmin (heavy chain $73 \%$, light chain $20 \%$, and preactivation peptide 7\%). The conversion of unlabeled glu-plasminogen into the glu-form, respectively, lys-form of plasmin, as judged from stained gels, was similar to that of ${ }^{125} \mathrm{I}$-glu-plasminogen.

Fibrinogen. Fibrinogen was rendered plasminogen poor by passage over lysine-Sepharose 4B. About $2 \mu \mathrm{g}$ of plasminogen were detectable per milligram of fibrinogen by the chromogenic substrate assay. Rocket immunoelectrophoresis in $1 \%$ agarose containing an antiserum against human Factor XIII demonstrated that the plasminogen-poor fibrinogen $(2 \mathrm{mg} / \mathrm{ml})$ contained 5-10\% of Factor XIII a subunit and b subunit as compared with normal plasma.

Plasminogen activator. Pig heart t-PA was purified as previously described (24). It moved as a single band on reduced and nonreduced SDS-PAGE $\left(M_{\mathrm{r}}\right.$ of 68,000$)$. In analogy to highly pure high $M_{\mathrm{r}}$ urokinase, we assigned arbitrarily a specific activity of $100,000 \mathrm{U} / \mathrm{mg}$ to highly purified pig heart t-PA. Therefore, in this work, $1 \mathrm{U}$ equals $10 \mathrm{ng}$ of pig heart t-PA. Comparison with the International Standard for t-PA which was established in June 1984 by the expert committee of biological standardization of the World Health Organization revealed that in the fibrin plate assay, $1 \mathrm{U}$ of pig heart t-PA equals $3.4 \mathrm{IU}$ of t-PA. DFP-inactivated $\mathrm{t}-\mathrm{PA}\left(1 \mathrm{~h}\right.$ incubation at $37^{\circ} \mathrm{C}$ with $10 \mathrm{mM}$ DFP) did not exhibit any activity in clot lysis or fibrin plate assays.

Binding studies of plasminogen to clots. Plasma clots were formed by the addition of $1 \mathrm{U} / \mathrm{ml}$ thrombin to plasma, with or without added $\mathrm{CaCl}_{2}$ (10 mM for citrated plasma and $20 \mathrm{mM}$ for citrated-EDTA plasma). $0.46 \mathrm{ml}$ of plasma, containing ${ }^{125} \mathrm{I}$-plasminogen $(100,000$ $\mathrm{cpm} / \mathrm{ml}$ ), were rapidly mixed with $10 \mu \mathrm{l}$ of $500 \mathrm{mM} \mathrm{CaCl}_{2}, 10 \mu \mathrm{l}$ of $50 \mathrm{U} / \mathrm{ml}$ thrombin, and $20 \mu \mathrm{l}$ of various concentrations of t-PA. After incubation at $37^{\circ} \mathrm{C}$ for various periods of time, clots were compacted with a plastic spatula, washed in $2 \mathrm{ml}$ of imidazole buffer containing 
1 mM EDTA, and dried on absorbant paper. The amount of plasminogen bound to the clots was expressed in percentage of added radioactivity. In one experiment, FSF-deficient plasma alone or supplemented with $20 \%$ normal plasma was used to study the effect of crosslinking on the t-PA induced uptake of plasminogen onto clots. For the study of the effect of aprotinin on the binding of plasminogen to plasma clots, $10 \mathrm{mg}$ of lyophilized aprotinin were added per milliliter of plasma pool $(117,000 \mathrm{KIU} / \mathrm{ml})$, which was then serially diluted in the same plasma.

Fibrin clots were made the same way as plasma clots from a fibrinogen solution $(2 \mathrm{mg} / \mathrm{ml}$ imidazole buffer) containing $1 \%$ BSA, glu-plasminogen $(0.2 \mathrm{mg} / \mathrm{ml})$, and ${ }^{125} \mathrm{I}$-plasminogen $(100,000 \mathrm{cpm} / \mathrm{ml})$ with or without $\alpha_{2}$ PI $(0.07 \mathrm{mg} / \mathrm{ml})$.

Clot lysis assays. The relationship between t-PA concentration and clot lysis time was studied as follows: plasma clots were made as described above in the presence of various t-PA concentrations. After thorough mixing the tubes were incubated at $37^{\circ} \mathrm{C}$ until complete solubilization of the clots had occurred. A straight line was obtained when the inverse of lysis time was plotted against the t-PA concentration.

To determine whether t-PA-induced accumulation of plasminogen preceded clot lysis, ${ }^{125}$ I-fibrinogen $(100,000 \mathrm{cpm} / \mathrm{ml}$, radiolabel 80 90\% clottable, $90-95 \%$ precipitable in $10 \%$ trichloroacetic acid) was added to plasma before the addition of $\mathrm{CaCl}_{2}$, thrombin, and t-PA or buffer. The clots were incubated at $37^{\circ} \mathrm{C}$ up to $360 \mathrm{~min}$, squeezed against the tube wall, washed, and dried on filter paper. The radioactivity was then determined. In the absence of t-PA, recovery of ${ }^{125} I$ in the clots remained $80-90 \%$ over the entire incubation period. Lysis of $t-$ PA containing clots was expressed as percent reduction of clot-bound ${ }^{125} \mathrm{I}$ in comparison with clots made in the absence of t-PA (8).

Electrophoretic procedure and radioautography. The nature of ${ }^{125}$ I-plasmin(ogen) forms bound to crosslinked clots was studied by SDS-PAGE of the solubilized clot followed by radioautography. SDSPAGE was performed as described by Laemmli (25), using a $10 \%$ polyacrylamide separating gel of $12.7 \times 14 \times 0.15 \mathrm{~cm}$ and a $4 \%$ polyacrylamide stacking gel. Crosslinked clots were solubilized by boiling the washed and dried clots at $100^{\circ} \mathrm{C}$ for $10 \mathrm{~min}$ in $0.5 \mathrm{ml}$ of $10 \mathrm{M}$ urea, 10\% SDS, and 10\% 2-mercaptoethanol. The solubilized samples were mixed with $0.125 \mathrm{ml}$ of $50 \%$ glycerol and $0.64 \mathrm{ml}$ of sample buffer containing $0.125 \mathrm{M}$ Tris- $\mathrm{HCl}, \mathrm{pH} 6.8,4 \%$ SDS, $20 \%$ glycerol, and $0.02 \%$ bromophenol blue. $0.1 \mathrm{ml}$ of the mixture was subjected to SDS-PAGE. After electrophoresis the gels were stained in a $0.25 \%$ solution of Coomassie Brilliant Blue R-250 in $\mathrm{H}_{2} \mathrm{O}$, methanol, acetic acid (4:4:1), and destained in the same solution without Coomassie Brilliant Blue. Radioautography was performed by exposing the dried gels to Kodak RPO2 X-ray film (Eastman Kodak Co., Rochester, NY) in the presence of intensifying screens (CAWO, SE 2) at $-70^{\circ} \mathrm{C}$ for 2-5 d. After radioautography the gels were cut into 2-mm strips. The radioactivity of each strip was determined to estimate the relative amount of the different forms of plasminogen and plasmin bound to clots.

\section{Results}

Influence of $t-P A$ on the binding of plasminogen to clots. Fig. 1 shows that t-PA induced a progressive uptake of radioiodinated plasminogen to fibrin clots. The rate of plasminogen accumulation on the clot was t-PA concentration dependent but maximum binding never exceeded $50 \%$, regardless of the $\mathrm{t}-\mathrm{PA}$ concentration. In the absence of $\mathrm{t}-\mathrm{PA}$, the amount of

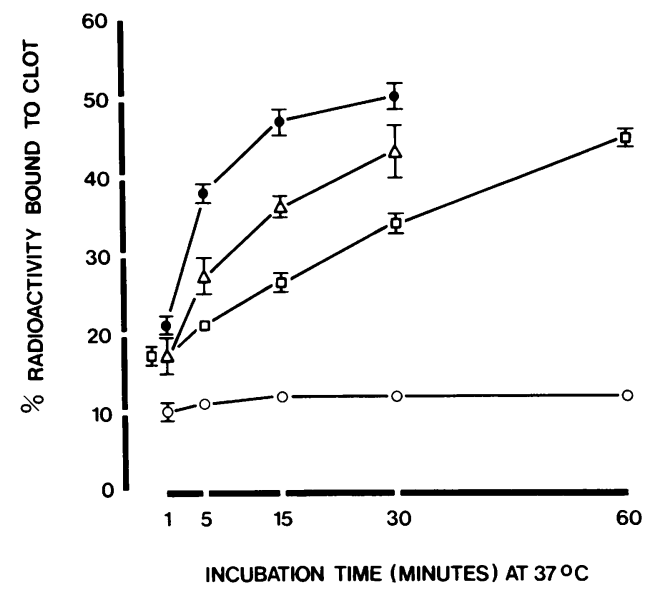

Figure 1. Effect of t-PA on the binding of plasminogen to fibrin clots. Clots were formed by the addition of $10 \mu \mathrm{l}$ of $\mathrm{CaCl}_{2}(500 \mathrm{mM}), 10 \mu \mathrm{l}$ of thrombin $(50 \mathrm{U} / \mathrm{ml})$, and $20 \mu \mathrm{l}$ of buffer or a t-PA containing solution to $0.46 \mathrm{ml}$ of a solution of fibrinogen $(2 \mathrm{mg} / \mathrm{ml}$ imidazole buffer) containing $1 \% \mathrm{BSA}, 0.2 \mathrm{mg} / \mathrm{ml}$ of glu-plasminogen, and ${ }^{125} \mathrm{I}-$ glu-plasminogen $(100,000 \mathrm{cpm} / \mathrm{ml})$. Clots were made in the absence (O) or in the presence of $3 \mathrm{U} / \mathrm{ml}(\bullet), 1.5 \mathrm{U} / \mathrm{ml}(\Delta)$, and $0.75 \mathrm{U} / \mathrm{ml}$ (ㅁ) of t-PA. After incubation at $37^{\circ} \mathrm{C}$, clots were squeezed with a plastic spatula, washed in $2 \mathrm{ml}$ of imidazole buffer containing $1 \mathrm{mM}$ EDTA, and dried on absorbant paper. Clot-bound plasminogen is expressed as percentage of total radioactivity added. The mean \pm SD of quadruplicate experiments are given. At t-PA concentrations $\geq 1.5$ $\mathrm{U} / \mathrm{ml}$ clot lysis occurred within $60 \mathrm{~min}$.

clot-bound plasminogen remained at $\sim 10 \%$ regardless of the incubation time.

A similar t-PA-induced accumulation of plasminogen was observed on plasma clots (Fig. 2). The maximum amount of clot-bound plasminogen, in the presence of $3 \mathrm{U} / \mathrm{ml} \mathrm{t}-\mathrm{PA}$, was comparable with that observed on fibrin clots, but the maximum was only attained after $240 \mathrm{~min}$ instead of $30 \mathrm{~min}$ incubation time. At $360 \mathrm{~min}$ there was a slight decrease in clot-bound radioactivity due to partial lysis of the clot. Effectively, when clots made under the same conditions were labeled with ${ }^{125}$ I-fibrin(ogen), no lysis occurred up to 120 min incubation, whereas, respectively, 5 and $10 \%$ lysis was measured at 240 and $360 \mathrm{~min}$ incubation. No increase in plasminogen binding to plasma clots was observed in the absence of t-PA. There was good correlation $(r>0.9)$ between the amount of ${ }^{125} \mathrm{I}$-plasminogen bound to plasma clots made in the presence of various t-PA concentrations after $30 \mathrm{~min}$ at $37^{\circ} \mathrm{C}$, and the reciprocal of the lysis time of clots made under the same conditions but incubated until complete solubilization had occurred (Fig. 3).

Aprotinin inhibited the t-PA-induced accumulation of plasminogen to plasma clots in a concentration dependent manner but had no influence on plasminogen uptake in the absence of t-PA (Fig. 4).

DFP-inactivated t-PA did not produce any increase in clot- 


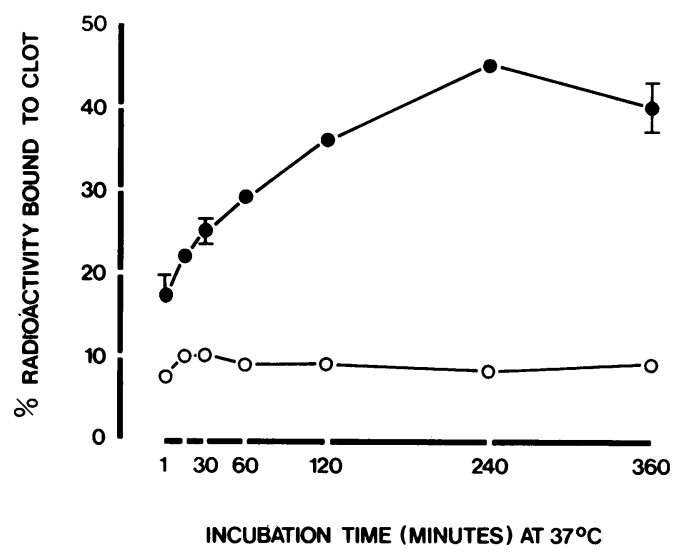

Figure 2. Effect of t-PA on the binding of plasminogen to plasma clots. Clots were made by the addition of $10 \mu \mathrm{l}$ of $\mathrm{CaCl}_{2}(500 \mathrm{mM})$, $10 \mu \mathrm{l}$ of thrombin $(50 \mathrm{U} / \mathrm{ml})$, and $20 \mu \mathrm{l}$ of buffer or a t-PA containing solution to $0.46 \mathrm{ml}$ citrated plasma containing ${ }^{125} \mathrm{I}$-plasminogen $(100,000 \mathrm{cpm} / \mathrm{ml})$. Clots were made in the absence of t-PA (0) or in the presence of $3 \mathrm{U} / \mathrm{ml}$ of t-PA (๑), and incubated up to $360 \mathrm{~min}$ at $37^{\circ} \mathrm{C}$. Otherwise as described in Fig. 1.

bound plasminogen. When plasma clots were formed in the presence of $100 \mathrm{mM}$ EACA the amount of clot-bound radioactivity was $<3 \%$, both in the presence and absence of t-PA (Fig. 5).

Identification of the forms of plasmin(ogen) bound to plasma clots. SDS-PAGE analysis and radioautography of solubilized clots allowed the identification of different forms of plasminogen and plasmin bound to clots. The upper part of Fig. 6 shows that, in the presence of $3 \mathrm{U} / \mathrm{ml}$ of t-PA, mainly glu-plasminogen and glu-plasmin accumulated on plasma clots. Comparing the positions of lys-plasminogen, lane 1 , and of lys-plasmin, lane 5, in Fig. 6, top, with those of the two major bands of lane 6 and 7 , and taking into account the comparable labeling efficiency of the heavy chain regions of glu- and lys-plas-

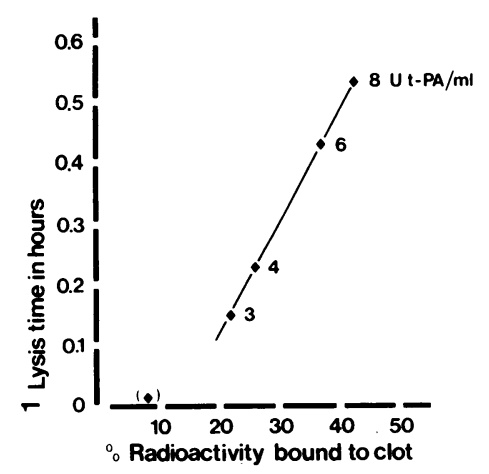

Figure 3. Correlation between the ${ }^{125}$ I-plasminogen uptake on plasma clots made in the presence of various t-PA concentrations and the reciprocal of the lysis time of clots made under the same conditions. Clots were made as described in Fig. 2 in the absence or in the presence of $8,6,4$, and $3 \mathrm{U} / \mathrm{ml}$ of t-PA. After $1 \mathrm{~h}$ incubation at $37^{\circ} \mathrm{C}$, the percentage of ${ }^{125}$ I-plasminogen uptake on the clots was determined as described in Fig. 1. The lysis time of clots was determined at the time of their complete solubilization. ( $\bullet$ ): in the absence of t-PA, clots did not lyse within 48 hours of observation.

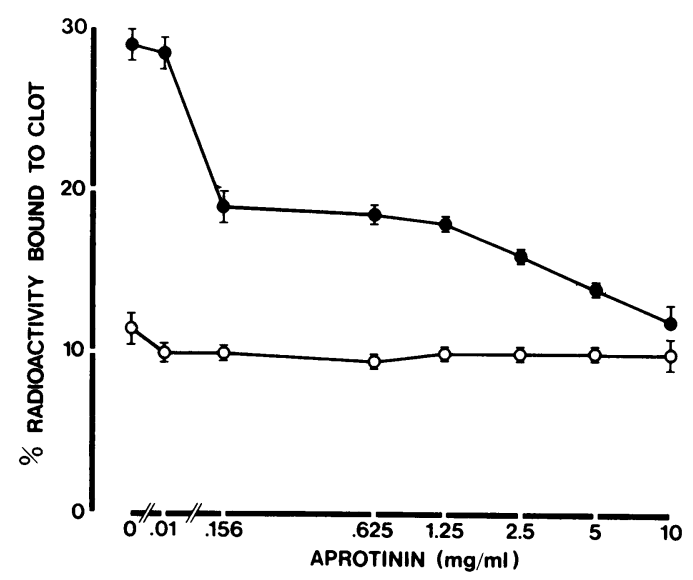

Figure 4. Effect of aprotinin on the plasminogen uptake by plasma clots. Clots were made from citrated plasma containing various concentrations of aprotinin in the absence $(0)$ or presence $(\bullet)$ of $3 \mathrm{U} / \mathrm{ml}$ of t-PA and incubated at $37^{\circ} \mathrm{C}$ for $4 \mathrm{~h}$. Otherwise as described in Fig. 2.

min(ogen) (see Methods), it appears that a minimal amount of lys-plasminogen bound to fibrin. The lower part of Fig. 6 demonstrates the time course of glu-plasminogen and gluplasmin uptake. Over a period of $6 \mathrm{~h}$, a band of weak intensity appeared progressively at the top of the gel consisting of plasmin- $\alpha_{2}$ PI complexes crosslinked to $\alpha$-chain polymers of fibrin (see also Fig. 10). After $120 \mathrm{~min}$ incubation, very weak bands appeared in the position of the lys-plasmin heavy chain and in the 50,000-55,000 mol wt range. In the absence of t-PA, only a faint band of plasmin- $\alpha_{2} P I$ crosslinked to the $\alpha$-chain polymers of fibrin, and small amounts of glu-plasminogen were apparent on the radioautography (last lane on the right, lower part of Fig. 6, and Fig. 7).

Quantitative analysis of the different forms of plasmin(ogen)

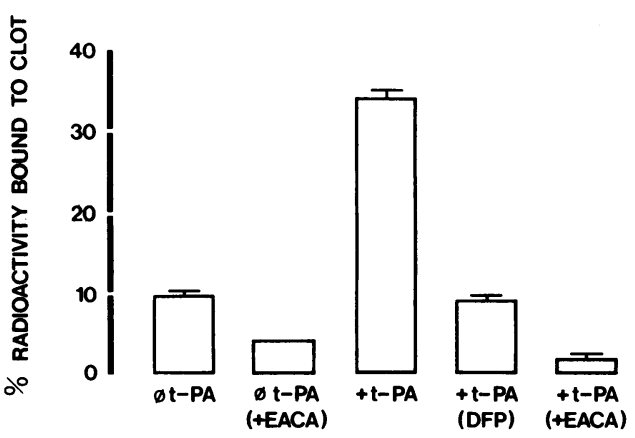

Figure 5. Effect of EACA and DFP-inactivated t-PA on the binding of plasminogen to plasma clots. Clots were made from citrated plasma as described in Fig. 2, in the presence or absence of $3 \mathrm{U} / \mathrm{ml}$ of active t-PA or DFP-inactivated t-PA. +EACA: clots were made from plasma containing $100 \mathrm{mM}$ of EACA. All clots were incubated at $37^{\circ} \mathrm{C}$ for $2 \mathrm{~h}$. Otherwise as described in Fig. 2. 

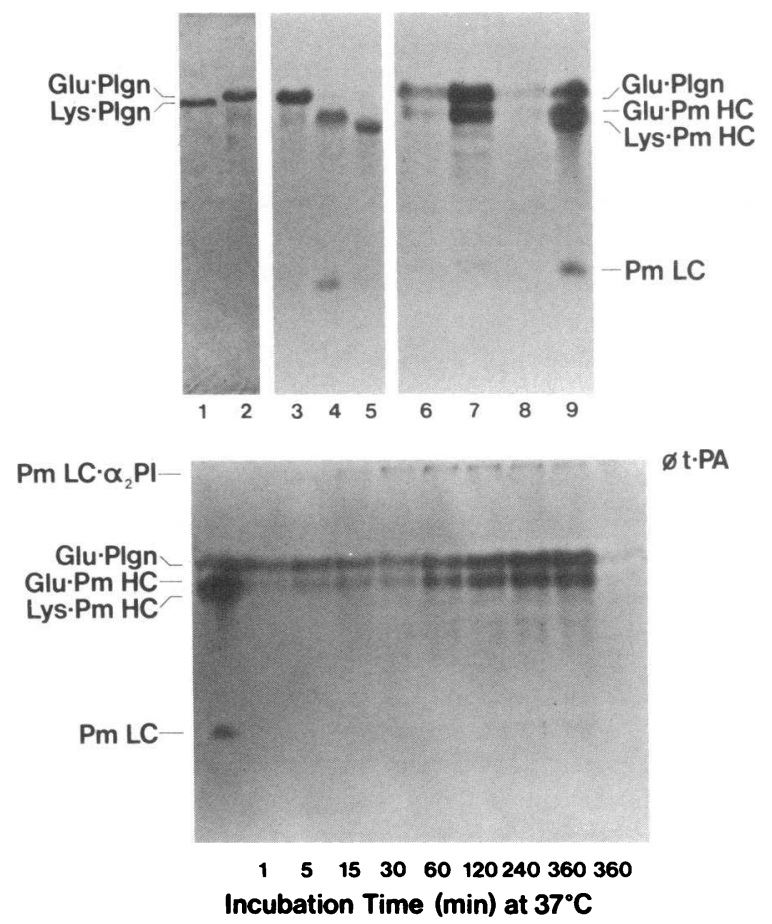

Figure 6. Identification of molecular species of clot-bound plasmin(ogen). Clots, made in the absence or presence of t-PA as described in Fig. 2, were solubilized and subjected to SDS-PAGE under reducing conditions followed by radioautography. Top: 1 and 2 Coomassie Blue stains, 3-9 radioautographies. 1: lys-plasminogen; 2: glu-plasminogen; 3: ${ }^{125} \mathrm{I}$-glu-plasminogen diluted in unlabeled gluplasminogen; 4 and 5: ${ }^{125} \mathrm{I}$-glu-plasmin and ${ }^{125} \mathrm{I}$-lys-plasmin prepared as described in Methods; 6 and 7: solubilized plasma clots made in the presence of $3 \mathrm{U} / \mathrm{ml}$ of t-PA after 1 and $360 \mathrm{~min}$ incubation at $37^{\circ} \mathrm{C}$; 8: solubilized plasma clot made in the absence of t-PA after $360 \mathrm{~min}$ incubation at $37^{\circ} \mathrm{C} ; 9$ : mixture of 3,4 , and 5. Bottom: First lane on the left: see lane 9, Top: 1-360: solubilized plasma clots made in the presence of $3 \mathrm{U} / \mathrm{ml}$ of t-PA, as described in Fig. 2, and incubated at $37^{\circ} \mathrm{C}$ for the indicated periods of time. Last lane on the right: solubilized plasma clot made in the absence of t-PA after 360 min incubation at $37^{\circ} \mathrm{C}$. Plgn, plasminogen; $\mathrm{Pm}$, plasmin; HC, heavy chain; LC, light chain.

bound to plasma clots. Fig. 7 illustrates the quantitative determination of various forms of ${ }^{125} \mathrm{I}$-plasmin(ogen) bound to plasma clots which had been incubated for $360 \mathrm{~min}$ at $37^{\circ} \mathrm{C}$ in the presence or absence of t-PA. The same bands as described in Fig. 6 were detectable by radioautography. In the presence of t-PA the percentage of radioactivity bound for each major band was: $8 \%$ for the plasmin- $\alpha_{2}$ PI complex (Fig. $7: 1$ ), $25 \%$ for glu-plasminogen (a clear distinction between this band and small amounts of lys-plasminogen was not possible) (Fig. 7:2), 36\% for the different forms of the heavy chain of plasmin (Fig. 7:3, 23\% for the glu-plasmin heavy chain, 5\% for the lys-plasmin heavy chain, $8 \%$ for the iodinated (degradation ?) products in the $50,000-55,000$ molecular weight

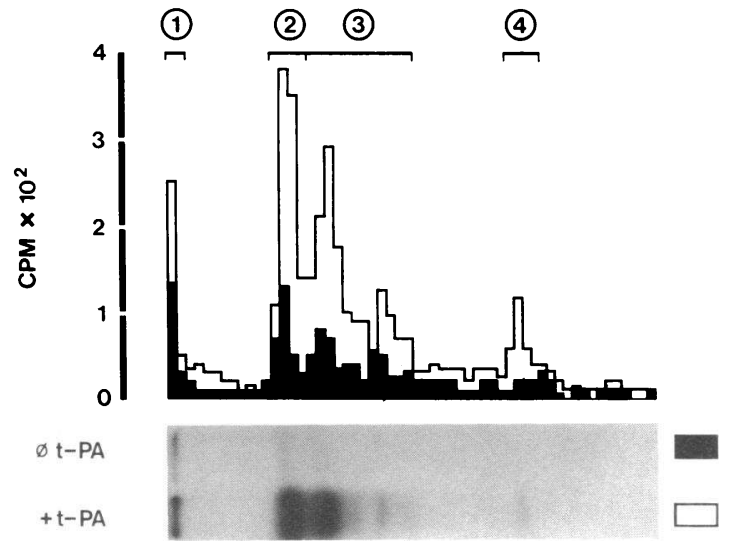

Figure 7. Procedure for the quantitative estimation of plasminogen and plasmin accumulated onto clots. Plasma clots were made in the presence of $3 \mathrm{U} / \mathrm{ml}$ of t-PA (open bars) or in the absence of t-PA (closed bars) and incubated at $37^{\circ} \mathrm{C}$ for $360 \mathrm{~min}$. After solubilization of the clots, SDS-PAGE and radioautography were performed. The dried gel was cut into 2-mm strips, and each strip was counted for radioactivity. The following forms of plasmin(ogen) were identified: 1: plasmin- $\alpha_{2}$ PI complex crosslinked to the $\alpha$-chain polymers of fibrin; 2: glu-plasminogen; 3: heavy chain of glu- and lys-plasmin and degradation products of $M_{\mathrm{r}}$ of 50,000-55,000; 4: plasmin light chain.

range), and $7 \%$ for the plasmin light chain (Fig. 7:4); $24 \%$ of the total radioactivity could not be attributed to distinct peaks. Total radioactivity bound was three times lower in the absence of t-PA and distributed mainly into the plasmin- $\alpha_{2}$ PI complex (12\%), glu-plasminogen (18\%), glu-plasmin heavy chain (16\%), lys-plasmin heavy chain (4\%), and the 50,000-55,000 molecular weight range species $(10 \%)$. Using this methodology, the quantity of each of the various molecular forms of fibrin-bound ${ }^{125}$ I-plasmin(ogen) was determined at different time intervals (Fig. 8). There was an initial phase of up to $30 \mathrm{~min}$ in which the fraction of glu-plasminogen that initially constituted $35 \%$ of the total clot-bound radioactivity decreased to $20 \%$ while the plasmin- $\alpha_{2}$ PI complex increased progressively and, after 60 min, reached a constant level of $\sim 10 \%$ of the clot-bound radioactivity. ${ }^{125}$ I-plasmin remained constant at $\sim 40 \%$ of clotbound radioactivity during the first $30 \mathrm{~min}$. After this initial lag phase there was progressive increase in glu-plasminogen and particularly in glu-plasmin uptake to, respectively, 25 and $55 \%$ of the total clot-bound radioactivity.

Influence of crosslinking on the t-PA-induced uptake of plasminogen to fibrin. During coagulation, in the presence of calcium ions, FSF brings about the crosslinking of fibrin and of $\alpha_{2}$ PI to the $\alpha$-chains of fibrin $(1,26-28)$. Since crosslinked $\alpha_{2}$ PI still preserves its capacity to inhibit plasmin (2), we studied the effect of crosslinking of fibrin on the t-PA induced plasminogen binding to fibrin. In a FSF-deficient plasma, no difference was observed in the t-PA-induced ${ }^{125} \mathrm{I}$-plasminogen uptake onto clots formed in the presence or absence of calcium ions. In clots made from FSF-deficient plasma supplemented 


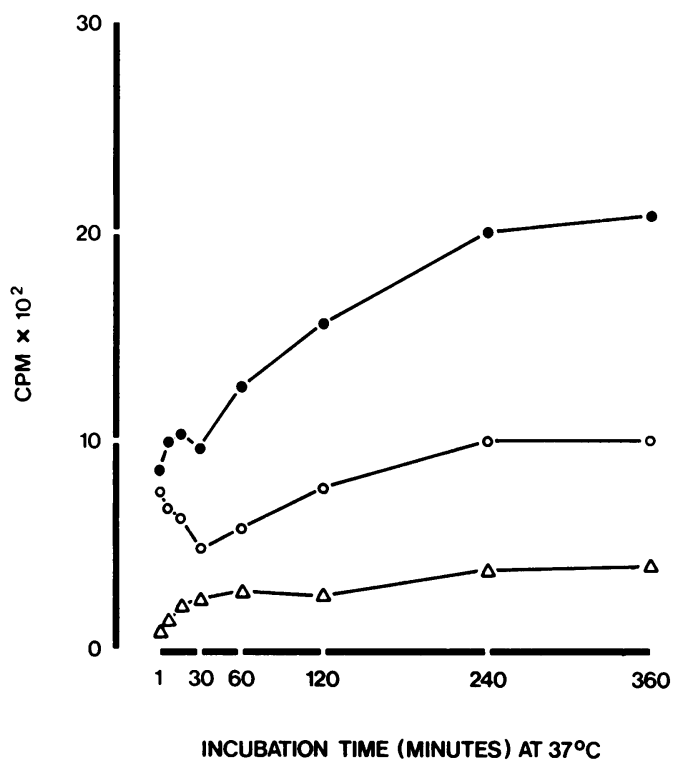

Figure 8. Kinetic analysis of the three major forms of clot-bound plasmin(ogen). Procedure as described in Fig. 7. The radioactivity of the three major plasmin(ogen) species is illustrated at each time point: (๑) heavy and light chains of plasmin; ( 0 ) glu-plasminogen; $(\Delta)$ plasmin- $\alpha_{2}$ PI complex.

with $20 \%$ normal plasma, the uptake was higher in the absence than in the presence of calcium ions as was observed in normal plasma clots (Fig. 9). When crosslinked fibrin clots were formed at a t-PA concentration of $1.5 \mathrm{U} / \mathrm{ml}$ and in the presence of a physiological concentration of $\alpha_{2} \mathrm{PI}, 13 \%$ of ${ }^{125}$ I-plasminogen bound to clots after $30 \mathrm{~min}$ incubation at $37^{\circ} \mathrm{C}$, whereas $45 \%$ binding occurred in the absence of $\alpha_{2} \mathrm{PI}$.

The right hand side of Fig. 10 illustrates an SDS-PAGE of a redissolved crosslinked ${ }^{125}$ I-fibrin clot. The high molecular weight band at the top corresponds to the $\alpha$-chain polymers of ${ }^{125}$ I-fibrin (29) and had the same mobility as the ${ }^{125} \mathrm{I}-$ plasminogen-derived high molecular weight band observed in crosslinked plasma clots and in $\alpha_{2}$ PI containing fibrin clots.

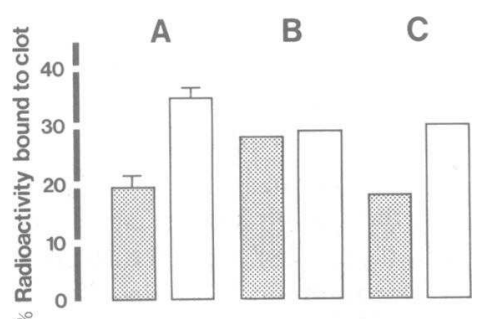

Figure 9. Binding of plasminogen to clots made from $(A)$ normal plasma; (B) FSF-deficient plasma; (C) 1 vol of normal plasma mixed with 4 vol of FSFdeficient plasma. Clots were made from citrated $(10$ mM)-EDTA (10 mM) plasma containing 1.5

$\mathrm{U} / \mathrm{ml}$ of t-PA, with (closed columns) or without (open columns) 20 $\mathrm{mM} \mathrm{Ca}{ }^{++}$added. Clots were incubated at $37^{\circ} \mathrm{C}$ for $30 \mathrm{~min}$. Otherwise as described in Figs. 1 and 2.

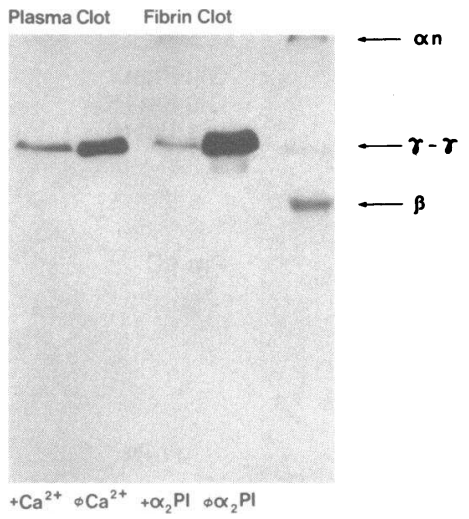

Figure 10. Identification of plasmin- $\alpha_{2}$ PI complex crosslinked to the $\alpha$-chain polymers of fibrin. Plasma clots were made from citrated $(10 \mathrm{mM})$-EDTA $(10$ $\mathrm{mM}$ ) plasma by the addition of $1 \mathrm{U} / \mathrm{ml}$ of thrombin, with or without $\mathrm{CaCl}_{2}$ $(20 \mathrm{mM})$, and in the presence of $1.5 \mathrm{U} / \mathrm{ml}$ of $\mathrm{t}-\mathrm{PA}$ and ${ }^{125} \mathrm{I}$-glu-plasminogen $(100,000 \mathrm{cpm} / \mathrm{ml})$. Fibrin clots were made in the presence of $1.5 \mathrm{U} / \mathrm{ml}$ of t-PA from a plasminogen-poor fibrinogen solution $(2 \mathrm{mg} / \mathrm{ml})$ to which were added $10 \mathrm{mM}$ EDTA, $20 \mathrm{mM} \mathrm{CaCl}, 0.2 \mathrm{mg} / \mathrm{ml}$ of gluplasminogen, and ${ }^{125} \mathrm{I}$-glu-plasminogen $(100,000 \mathrm{cpm} / \mathrm{ml})$ with or without $0.07 \mathrm{mg} / \mathrm{ml}$ of $\alpha_{2} \mathrm{PI}$. Clots were incubated at $37^{\circ} \mathrm{C}$ for 30 min, solubilized, and subjected to SDS-PAGE and radioautography. The last lane depicts the autoradiography of a redissolved fibrin clot, made as the $\alpha_{2}$ PI containing fibrin clot described above, to which ${ }^{125} \mathrm{I}$-fibrinogen $(100,000 \mathrm{cpm} / \mathrm{ml})$ had been added instead of the ${ }^{125} \mathrm{I}$ plasminogen. $\alpha \mathrm{n}, \alpha$-chain polymers of crosslinked fibrin; $\gamma-\gamma, \gamma-$ chain dimers of fibrin; $\beta, \beta$-chains of fibrin.

This band was not observed when the presence of EDTA in plasma clots did not allow crosslinking of $\alpha_{2}$ PI to the $\alpha$-chain polymers or when $\alpha_{2}$ PI was absent in crosslinked fibrin clots. This observation suggests that the radiolabeled plasmin light chain complexes with the $\alpha_{2}$ PI crosslinked to the $\alpha$-chain polymers of fibrin.

\section{Discussion}

Clot lysis results from the dissolution of the fibrin network brought about by plasmin. The simultaneous absorption of plasminogen and t-PA onto fibrin during clotting facilitates the degradation of fibrin $(3,4,11)$. Several studies including this one have shown that $\sim 5-10 \%$ of plasmatic glu-plasminogen (equivalent to $0.2 \mu \mathrm{M})$ binds to a plasma clot $(2,12-15)$. It is interesting to note that an equimolar amount of $\alpha_{2}$ PI crosslinks to plasma clots (2). This explains why normal plasma clots do not lyse spontaneously $(2,8)$. The cleavage by plasmin of a 76 residue peptide from the amino-terminal end of gluplasminogen results in lys-plasminogen (30). The latter binds more strongly to fibrin (31) and is more rapidly activated into plasmin than glu-plasminogen $(3,4,32,33)$. Some authors have postulated that the conversion of the glu- into the lysform is a prerequisite for an increased uptake of plasminogen onto fibrin. Such a mechanism would enhance the formation of fibrin-bound plasmin and thus the dissolution of fibrin (18, 34-36). However our study demonstrates that fibrinolysis induced by porcine t-PA is conditioned by a progressive 
accumulation onto fibrin of mainly glu-plasmin(ogen) and not of lys-plasmin(ogen). The described mechanism was also actuated in clots made from plasma rich in plasminogen activator which was obtained from human volunteers after infusion of deamino-D-arginine-vasopressine, or from normal plasma to which human melanoma cell line derived t-PA had been added (data not shown). Our methodology did not allow detection of the eventual presence of small amounts of clotbound lys-plasminogen. Attempts to distinguish glu- and lysplasminogen by urea/acetic acid electrophoresis were unsuccessful, since fibrin interferes with the electrophoretic separation (12). The accumulation of glu-plasminogen took place before any significant lysis of fibrin had occurred and appeared to be specific. In the presence of EACA, only $3 \%$ of plasminogen was recovered in a clot, regardless of whether t-PA had been added or not. This was probably due to nonspecific trapping of plasminogen, since an equivalent amount of ${ }^{125} \mathrm{I}$-albumin is incorporated in clots $(31,37)$. The t-PA-induced uptake of plasminogen requires active t-PA; DFP-inactivated t-PA did not enhance the binding of plasminogen to fibrin.

The crosslinking process effectuated by activated FSF inhibited the plasminogen uptake induced by t-PA. Furthermore, the presence of $\alpha_{2} \mathrm{PI}$ in fibrin clots and/or in the surrounding milieu had the same effect. When plasma or fibrinogen was clotted under conditions allowing crosslinking of $\alpha_{2}$ PI to fibrin, radiolabeled plasmin(ogen), presumably plasmin light chain covalently linked to $\alpha_{2} \mathrm{PI}$, was found to be associated with the $\alpha$-chain polymers of fibrin. These three observations taken together suggest that the crosslinking of $\alpha_{2}$ PI to fibrin modulates the t-PA induced uptake of plasminogen to fibrin. Further studies will be needed, however, to determine whether free $\alpha_{2}$ PI contributes or not to this regulatory mechanism.

Aprotinin, a powerful plasmin inhibitor, decreased the t-PA-induced accumulation of plasminogen to fibrin at low concentrations which are known not to inhibit t-PA activity (38). Suenson et al. (23) have recently reported that fibrin prepared from fibrinogen which had been partially degraded by plasmin bound higher amounts of glu-plasminogen than nondegraded fibrin. Preliminary experiments in our own laboratory indicate that preformed fibrin which had been treated with plasmin for various lengths of time also takes up higher amounts of glu-plasminogen than native preformed fibrin (manuscript in preparation). These observations lend support to the hypothesis that t-PA induced accumulation of gluplasminogen is plasmin-mediated.

In conclusion, fibrinolysis induced by physiological concentrations of t-PA is preceded by an accumulation of gluplasminogen onto fibrin. On a molar basis, the amount of clot-bound plasmin(ogen) was up to five times that of $\alpha_{2} \mathrm{PI}$ crosslinked to fibrin. The accumulation of plasminogen does not require its conversion into the lys-form and is probably mediated by limited plasmin degradation of fibrin. Finally, the amount of clot-bound plasmin(ogen) determines the rate of clot lysis induced by t-PA.

\section{Acknowledgments}

We are indebted to Mrs. Jean Rochat and Mrs. Josette Guillemin for assistance in the preparation of this manuscript.

This work was supported in part by a grant from the Swiss National Fund for Scientific Research (No. 3.688-0.80).

\section{References}

1. Tamaki, T., and N. Aoki. 1981. Cross-linking of $\alpha_{2}$-plasmin inhibitor and fibronectin to fibrin by fibrin-stabilizing factor. Biochim. Biophys. Acta. 661:280-286.

2. Sakata, T., and N. Aoki. 1982. Significance of cross-linking of $\alpha_{2}$-plasmin inhibitor to fibrin in inhibition of fibrinolysis and in hemostasis. J. Clin. Invest. 69:536-542.

3. Hoylaerts, M., D. C. Rijken, H. R. Lijnen, and D. Collen. 1982. Kinetics of the activation of plasminogen by human tissue plasminogen activator. Role of fibrin. J. Biol. Chem. 257:2912-2919.

4. Rånby, M. 1982. Studies on the kinetics of plasminogen activation by tissue plasminogen activator. Biochim. Biophys. Acta. 704:461-469.

5. Matsuo, O., D. C. Rijken, and D. Collen. 1981. Comparison of the relative fibrinogenolytic, fibrinolytic and thrombolytic properties of tissue plasminogen activator and urokinase in vitro. Thromb. Haemostasis. 45:225-229.

6. Korninger, C., O. Matsuo, R. Suy, J. M. Stassen, and D. Collen. 1982. Thrombolysis with human extrinsic (tissue-type) plasminogen activator in dogs with femoral vein thrombosis. J. Clin. Invest. 69:573580.

7. Mattson, C., V. Nyberg-Arrhenius, and P. Wallén. 1981. Dissolution of thrombi by tissue plasminogen activator, urokinase and streptokinase in an artificial circulating system. Thromb. Res. 21:535545.

8. Tran-Thang, C., E. K. O. Kruithof, and F. Bachmann. 1984. The mechanism of in vitro clot lysis induced by vascular plasminogen activator. Blood. 63:1331-1337.

9. Wiman, B., and D. Collen. 1978. On the kinetics of the reaction between human antiplasmin and plasmin. Eur. J. Biochem. 84:573578.

10. Takada, A., T. Ito, and Y. Takada. 1980. Interaction of plasmin with tranexamic acid and $\alpha_{2}$-plasmin inhibitor in the plasma and clot. Thromb. Haemostasis. 43:20-23.

11. Wiman, B., and D. Collen. 1978. Molecular mechanism of physiological fibrinolysis. Nature (Lond.). 272:549-550.

12. Suenson, E., and S. Thorsen. 1981. Secondary-site binding of glu-plasmin, lys-plasmin, and miniplasmin to fibrin. Biochem. $J$. 197:619-628.

13. Lijnen, H. R., B. Van Hoef, and D. Collen. 1981. On the role of the carbohydrate side chains of human plasminogen in its interaction with $\alpha_{2}$-antiplasmin and fibrin. Eur. J. Biochem. 120:149-154.

14. Whitaker, A. N., E. A. Rowe, P. P. Masci, F. Joe, and P. J. Gaffney. 1980. The binding of glu- and lys-plasminogen to fibrin and their subsequent effects on fibrinolysis. Thromb. Res. 19:381-391.

15. Thorsen, S. 1975. Differences in the binding to fibrin of native plasminogen and plasminogen modified by proteolytic degradation influence of $\omega$-aminocarboxylic acids. Biochim. Biophys. Acta. 393: $55-65$.

16. Rákóczi, I., B. Wiman, and D. Collen. 1978. On the biological significance of the specific interaction between fibrin, plasminogen and antiplasmin. Biochim. Biophys. Acta. 540:295-300. 
17. Thorsen, S., I. Clemmensen, L. Sottrup-Jensen, and S. Magnusson. 1981. Adsorption to fibrin of native fragments of known primary structure from human plasminogen. Biochim. Biophys. Acta. 668:377-387.

18. Sakata, Y., J. Mimuro, and N. Aoki. 1984. Differential binding of plasminogen to crosslinked and noncrosslinked fibrins: its significance in hemostatic defect in factor XIII deficiency. Blood. 63:1393-1401.

19. Granelli-Piperno, A., and E. Reich. 1978. A study of proteases and protease-inhibitor complexes in biological fluids. J. Exp. Med. 148:223-234.

20. Deutsch, D. G., and E. T. Mertz. 1970. Plasminogen: purification from human plasma by affinity chromatography. Science (Wash. DC). 170:1095-1096.

21. Allen, G. 1981. Determination of peptide sequences. In Sequencing of Proteins and Peptides. T. S. Work and R. H. Burdon, editors. Elsevier/North-Holland Biomedical Press, Amsterdam. 168173.

22. Gaffney, P. J., M. Brasher, K. Lord, and T. B. L. Kirkwood. 1977. Activation of plasminogen as a feature in its assay. Haemostasis. 6:72-88.

23. Suenson, E., O. Lützen, and S. Thorsen. 1984. Initial plasmindegradation of fibrin as the basis of a positive feed-back mechanism in fibrinolysis. Eur. J. Biochem. 140:513-522.

24. Kruithof, E. K. O., C. Tran-Thang, A. Ransijn, and F. Bachmann. 1984. Demonstration of a fast-acting inhibitor of plasminogen activators in human plasma. Blood. In press.

25. Laemmli, U. K. 1970. Cleavage of structural proteins during the assembly of the head of bacteriophage T4. Nature (Lond.). 227:680685.

26. Sakata, Y., K. Tateno, T. Tamaki, and N. Aoki. 1979. Calciumdependent binding of $\alpha_{2}$-plasmin inhibitor to fibrin. Thromb. Res. 16:279-282.

27. Sakata, Y., and N. Aoki. 1980. Cross-linking of $\alpha_{2}$-plasmin inhibitor to fibrin by fibrin-stabilizing factor. J. Clin. Invest. 65:290297.

28. Tamaki, T., and N. Aoki. 1982. Cross-linking of $\alpha_{2}$-plasmin inhibitor to fibrin catalyzed by activated fibrin-stabilizing factor. $J$. Biol. Chem. 257:14767-14772.
29. Gladner, J. A., and R. Nossal. 1983. Effects of crosslinking on the rigidity and proteolytic susceptibility of human fibrin clots. Thromb. Res. 30:273-288.

30. Violand, B. N., and F. J. Castellino. 1976. Mechanism of the urokinase-catalyzed activation of human plasminogen. J. Biol. Chem. 251:3906-3912.

31. Lucas, M. A., L. J. Fretto, and P. A. McKee. 1983. The binding of human plasminogen to fibrin and fibrinogen. J. Biol. Chem. 258:4249-4256.

32. Wohl, R. C., L. Summaria, and K. C. Robbins. 1980. Kinetics of activation of human plasminogen by different activator species at pH 7.4 and $37^{\circ}$ C. J. Biol. Chem. 255:2005-2013.

33. Lucas, M. D., D. L. Straight, L. J. Fretto, and P. A. McKee. 1983. The effects of fibrinogen and its cleavage products on the kinetics of plasminogen activation by urokinase and subsequent plasmin activity. J. Biol. Chem. 258:12171-12177.

34. Thorsen, S., E. Suenson, S. Müllertz, and P. Kok. 1981. Transformation of plasminogen and the selective degradation of fibrin. In Progress in Fibrinolysis, Vol. V. J. F. Davidson, I. M. Nilsson, and B. Åstedt, editors. Churchill Livingstone, Edinburgh. 119-124.

35. Vali, Z., and L. Patthy. 1982. Location of the intermediate and high affinity w-aminocarboxylic acid-binding sites in human plasminogen. J. Biol. Chem. 257:2104-2110.

36. Lucas, M. A., L. J. Fretto, and P. A. McKee. 1983. The relationship of fibrinogen structure to plasminogen activation and plasmin activity during fibrinolysis. In Molecular Biology of Fibrinogen and Fibrin. M. W. Mosesson and R. F. Doolittle, editors. Ann. NY Acad. Sci. 408:71-91.

37. Tran-Thang, C., and F. Bachmann. 1981. Binding of lysplasminogen, lys-plasmin, streptokinase and of streptokinase-plasminogen complex to whole blood clots. In Progress in Fibrinolysis, Vol. V. J. F. Davidson, I. M. Nilsson, and B. Astedt, editors. Churchill Livingstone, Edinburgh. 363-367.

38. Rånby, M., N. Bergsdorf, and T. Nilsson. 1982. Enzymatic properties of the one- and two-chain form of tissue plasminogen activator. Thromb. Res. 27:175-183. 